\title{
The rich get richer: patterns of plant invasions in the United States
}

\author{
Thomas J Stohlgren, ${ }^{1}$ David T Barnett, ${ }^{2}$ and John T Kartesz ${ }^{3}$
}

\begin{abstract}
Observations from islands, small-scale experiments, and mathematical models have generally supported the paradigm that habitats of low plant diversity are more vulnerable to plant invasions than areas of high plant diversity. We summarize two independent data sets to show exactly the opposite pattern at multiple spatial scales. More significant, and alarming, is that hotspots of native plant diversity have been far more heavily invaded than areas of low plant diversity in most parts of the United States when considered at larger spatial scales. Our findings suggest that we cannot expect such hotspots to repel invasions, and that the threat of invasion is significant and predictably greatest in these areas.
\end{abstract}

Front Ecol Environ 2003; 1(1): 11-14

$\mathrm{S}^{\mathrm{n}}$ mall-scale experiments (Knops et al. 1997; Tilman 1999; Naeem et al. 2000; Kennedy et al. 2002) and mathematical models (Turelli 1981; Post and Pimm 1983; Rummel et al. 1983; Case 1990) have generally supported a long-held ecological paradigm that, in natural areas, habitats of low plant diversity are more vulnerable to plant invasions than areas of high diversity (Elton 1958). This theory contends that, through the process of competitive exclusion (Grime 1973), species-rich areas are "immunized" against invasion by foreign plants through the preemption of resources by native species (Tilman 1999). One recent study by Kennedy et al. (2002) found that "diverse communities will probably require minimal maintenance and monitoring because they are generally effective at excluding undesirable invaders".

It would be comforting to believe that areas with many plant species are less prone to invasion than those with fewer species. Botanical hotspots such as wetlands, riparian zones, Mediterranean environments, subtropical coastal areas, and tallgrass prairies might repel the frequent arrival of plants from other regions or countries. Mechanical, chemical, and biological control techniques might be limited to heavily invaded, species-poor areas, with little danger of compromising unique assemblages of native plant species.

Recently, some ecologists have begun to question this perspective (Stohlgren et al. 1997, 1999; Levine and D'Antonio 1999; Levine 2000). Casual observations have shown highly invasive plant species, including tamarisk (Tamarix spp.), Russian olive (Elaeagnus angustifolia), purple loostrife (Lythrum salicaria), and Chinese tallow (Sapium sebiferum), becoming widely established in

\footnotetext{
${ }^{1}$ National Institute of Invasive Species Science, US Geological Survey, Fort Collins Science Center, Fort Collins, CO 80526 (tom_stohlgren@usgs.gov); ${ }^{2}$ Natural Resource Ecology Laboratory, Colorado State University, Fort Collins, CO 80523; ${ }^{3}$ Biota of North America Program, University of North Carolina, Chapel Hill, NC 27599
}

species-rich riparian zones and wetlands. Until now, however, large, carefully collected data sets from natural landscapes have been unavailable. These are useful for comparing local, landscape, regional, and national patterns to those observed under carefully controlled conditions, such as heavily manipulated, small-scale, experimental plots protected from disturbance (Knops et al. 1997; Naeem et al. 2000; Kennedy et al. 2002).

\section{Methods}

We evaluated two large independent data sets on the distribution of native and non-native plant species. The first set was gathered from 316 large vegetation-monitoring plots in eight states, which are part of the USDA Forest Service's Forest Health Monitoring Program (Cline et al. 1995). The plots are systematically spaced throughout the US (one every $63942 \mathrm{ha}$ ), and the numbers vary by state: Colorado (33), Delaware (39), Michigan (71), Oregon (44), Pennsylvania (81), Virginia (15), Washington (12), and Wyoming (21). Each plot consists of four $168-\mathrm{m}^{2}$ subplots, with three $1-\mathrm{m}^{2}$ quadrats in each subplot. Between 1997 and 2001, all the plots were sampled once every summer. Data were collected on the presence and cover of native and non-native species in each quadrat and species presence in the subplots.

The second data set was gathered over the past 20 years by the Biota of North America Program (www.bonap.org) at the University of North Carolina, Chapel Hill. Data were available for 44 of 50 US states, and were based on over 229000 records of native and non-native plant species occurrences by county. The taxonomic accuracy and completeness of this data set have made it the standard reference for many governmental and non-governmental agencies.

Correlations were evaluated on log-transformed $\left(\log _{10}[X+1]\right)$ values of both native and non-native plant species at each spatial scale. Significant values in all cases 
Table 1. Correlations of native to non-native plant species richness at $1-\mathrm{m}^{2}$ (quadrat) scales and $672-\mathrm{m}^{2}$ (plot) scales for Forest Health Monitoring plots in eight states

\begin{tabular}{|c|c|c|c|c|c|c|c|c|}
\hline \multirow[b]{2}{*}{ State } & \multicolumn{4}{|c|}{$\mathrm{I}-\mathrm{m}^{2}$ scale } & \multicolumn{4}{|c|}{$672-m^{2}$ scale } \\
\hline & slope & $r$ & $P$ & $n$ & slope & $r$ & $P$ & $n$ \\
\hline Colorado & 0.002 & 0.005 & 0.932 & 340 & 0.510 & 0.360 & 0.040 & 33 \\
\hline Delaware & -0.003 & -0.005 & 0.918 & 398 & 0.270 & 0.190 & 0.248 & 39 \\
\hline Michigan & 0.017 & 0.038 & 0.426 & 448 & 0.033 & 0.018 & 0.883 & 71 \\
\hline Oregon & 0.009 & 0.013 & 0.810 & 348 & 0.763 & 0.443 & 0.003 & 44 \\
\hline Pennsylvania & 0.013 & 0.036 & 0.269 & 930 & 0.964 & 0.552 & 0.001 & 81 \\
\hline Virginia & 0.177 & 0.212 & 0.009 & $|5|$ & 0.829 & 0.530 & 0.042 & 15 \\
\hline Washington & 0.016 & 0.020 & 0.830 & 124 & 0.068 & 0.032 & 0.922 & 12 \\
\hline Wyoming & 0.075 & 0.160 & 0.019 & 219 & 0.642 & 0.310 & 0.173 & 21 \\
\hline Combined & 0.028 & 0.050 & 0.003 & 2958 & 0.543 & 0.330 & 0.001 & 316 \\
\hline
\end{tabular}

were based on $\alpha=0.05$ using Version 10 (2000) of the SYSTAT statistical software. County-scale correlations were not evaluated for states without sufficient data. State data not maintained by BONAP were not included in the state-scale correlations.

\section{Results and discussion}

\section{Plant neighborhood and plot scales}

Data from $1-\mathrm{m}^{2}$ quadrats in natural landscapes might provide insights on the success of establishment (presence) and growth (foliar cover) of native and non-native plants in close proximity - what might be called a plant's neighborhood. Based on the results of small-scale experiments at similar scales (Knops et al. 1997; Naeem et al. 2000; Kennedy et al. 2002), we might expect a negative correlation between native and non-native species richness in natural areas. However, US Forest Service Forest Health Monitoring data from the $1-\mathrm{m}^{2}$ quadrats showed slopes with positive trends (though they may not be significantly different from zero) rather than negative slopes in the correlations of native to non-native species richness in seven of eight states (Table 1). They also showed a highly significant positive relationship between native and non-native species richness for the 2958 quadrats in all states combined (Table 1). (Vegetation was not measured in subplots without trees.)

Cumulative species lists of native and non-native species from replicate plots might show the patterns of plant diversity and invasion in larger areas more clearly. Some field studies have shown that at least some species-rich vegetation types have been successfully invaded (Stohlgren et al. 1999, 2002). Plot-scale data from the Forest Health Monitoring program data in eight states strongly confirmed this pattern. The relationships between native and nonnative species richness were strongly positive, with significant positive relationships found for half the states tested, and for all states combined $(r=0.33, P<0.001$; Table 1$)$. Significant positive relationships also existed between native and non-native species richness and foliar cover. Foliar cover is another strong indicator of the success of invading species in capturing local resources for growth. For the 316 plots in the eight states, native plant species richness was significantly positively correlated to native foliar cover $(r=0.31$, $P<0.001$ ). Non-native species cover was significantly positively correlated to native species richness $(r=0.15, P<0.008)$, the opposite of what might be expected from controlled experiments (eg Naeem et al. 2000; Kennedy et al. 2002). Non-native species cover was even more significantly positively correlated to non-native species richness $(r=0.65, P<0.001)$. These results suggest that resident species richness at neighborhood and plot scales may not be an effective barrier to invasion in these widely dispersed natural communities.

\section{County- and state-level data}

The second data set included the occurrences of 2770 non-native plant species in 2798 counties in 44 states. When we correlated native to non-native species richness for all counties, we found positive correlations in 43 of 44 states, with 40 states having significant positive relationships (Figure 1).

We also evaluated the BONAP data at the state scale, and found a positive, nearly significant correlation between native and non-native species richness $(r=0.28, P=0.07)$. California had a strong effect on this correlation, but the data are accurate, the plant invasions are real, and we could not justify eliminating California as an outlier. Our findings strongly agree with global-scale results, which have reported even stronger positive relationships between native and non-native species richness in parks and natural areas $(r=0.83, P=0.001$; Lonsdale 1999).

\section{Widespread patterns of invasion}

Our analysis raises serious doubts that high native species richness somehow decreases an area's vulnerability to invasions by non-native plants. Even at the smaller scales of plant neighborhoods and most experimental studies (typically $1-\mathrm{m}^{2}$ ), there is little evidence of a negative relationship between native plant diversity and the establishment of invasive species (Table 1). It appears that the relationships are generally positive (they have positive slopes) and that they strengthen as the spatial scale increases, leading us to hypothesize that the competitive exclusion of invasive species by native species may be a particularly weak force in most environments. Speciesrich hotspots have been successfully invaded at multiple spatial scales. We should not expect sites, counties, or states high in native species richness to be less vulnerable to future invasions, despite valuable efforts to protect native species. Furthermore, non-native plant control efforts, whether mechanical, chemical, or biological, will have to be carefully targeted and even more carefully conducted in areas high in native species richness. 


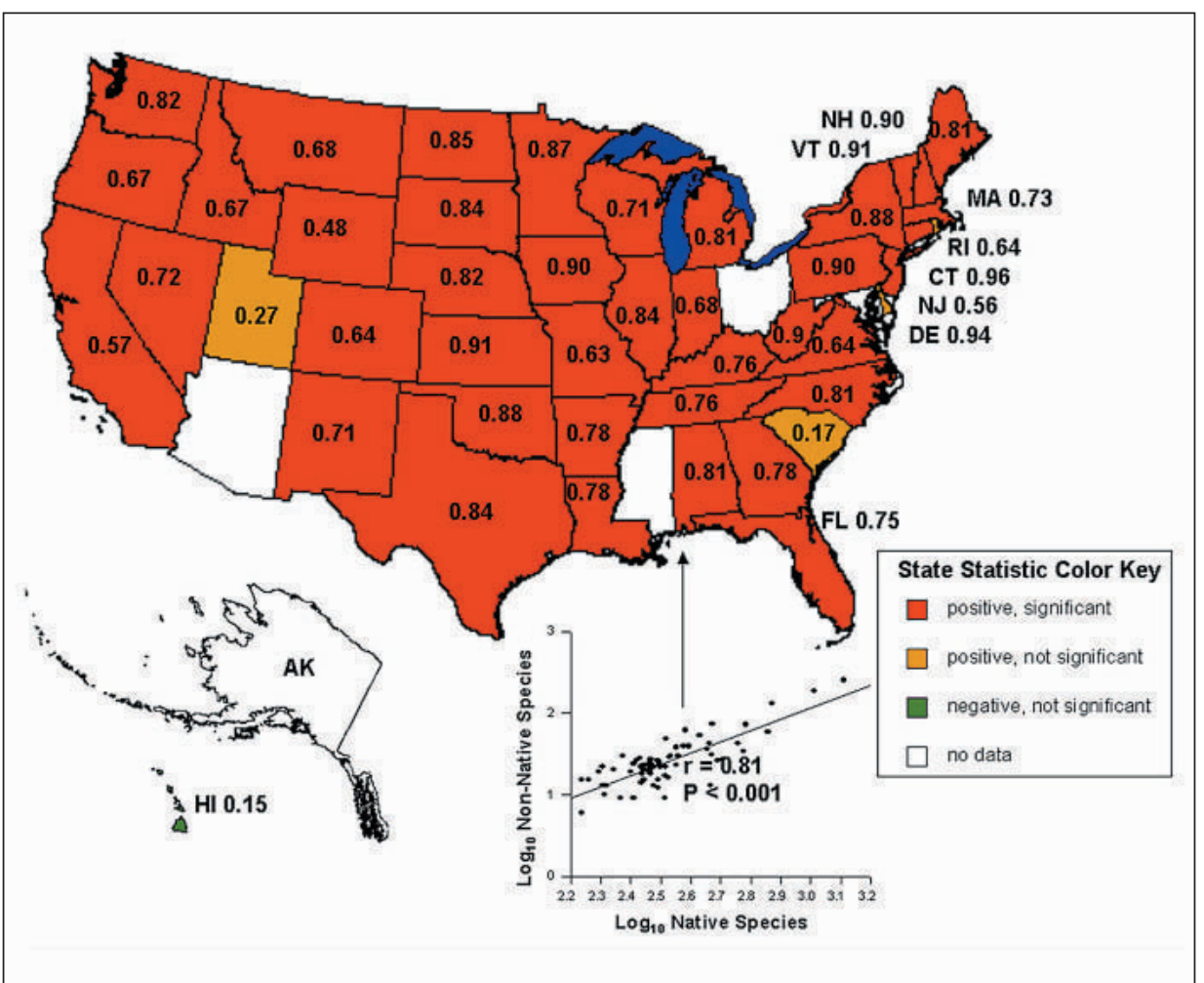

Figure 1. Correlation coefficient (r) of native to non-native plant species richness in counties for each state. Alabama is shown as an example. States in red indicate significant correlations $(\mathrm{P}<0.05)$ between native and non-native species, orange indicates non-significant positive correlations, and green (Hawaii) indicates a negative non-significant correlation. Countyscale correlations in Rhode Island and Delaware were not significant, probably due to small sample size ( $\mathrm{n}=5$ and 3 counties, respectively).

The positive relationships between native and invasive species richness cannot be expected in heavily invaded sites, since non-native species can obtain dominance and replace native species. This is the case in Hawaii, where less than half the flora are native species, and in some of California's annual grasslands, as well as in parts of Florida. In such cases, we would expect weaker relationships between native and non-native species (which is exactly what we found in Hawaii). There are global exceptions to this pattern as well. Tropical rain forests, with their dim understory levels, are poorly invaded, but tropical islands are more heavily invaded (Rejmánek 1996; Lonsdale 1999). Nevertheless, throughout the US (Table 1; Figures 1 and 2) and the world (Lonsdale 1999), species-rich areas have been heavily invaded.

There are additional reasons to be concerned about plant invasions in the US. The BONAP scientists' report adds about 300 species to the nation's flora count each year, through new accessions such as county records and newly reported species. Only about 10\% of the new accessions are native species (BONAP), suggesting that plant invasions in the US may be escalating. Invasive plants may bring insects and pathogens to new areas, including diseases such as sudden oak death (caused by the fungus-like organism Phytophthora ramorum), Dutch elm disease, and white pine blister rust. In the face of increasing invaders, it is troubling to consider how many empty niches and vulnerable habitats and populations there are in natural ecosystems. Landuse change, disturbance, high propagule pressure, and many other factors may be associated with the invasion patterns observed at quadrat, plot, county, and statewide scales. Regardless of their causes, it is clear that the success of plant invasions (as measured by non-native species richness and cover) is significantly greater at sites rich in native species.

\section{Conclusions}

In general, areas high in native species richness also support larger numbers of non-native species - in other words, "the rich get richer". We believe, as do others (Rejmánek 1989, 1996, 1999; Levine and D'Antonio 1999; Lonsdale 1999; Levine 2000), that there may be no direct cause-effect relationship between native and non-native species richness. However, high native species richness may be indirectly, but positively, correlated to habitat heterogeneity, by increasing available resources (Davis et al. 2000); high species turnover (many populations with few individuals are more likely to

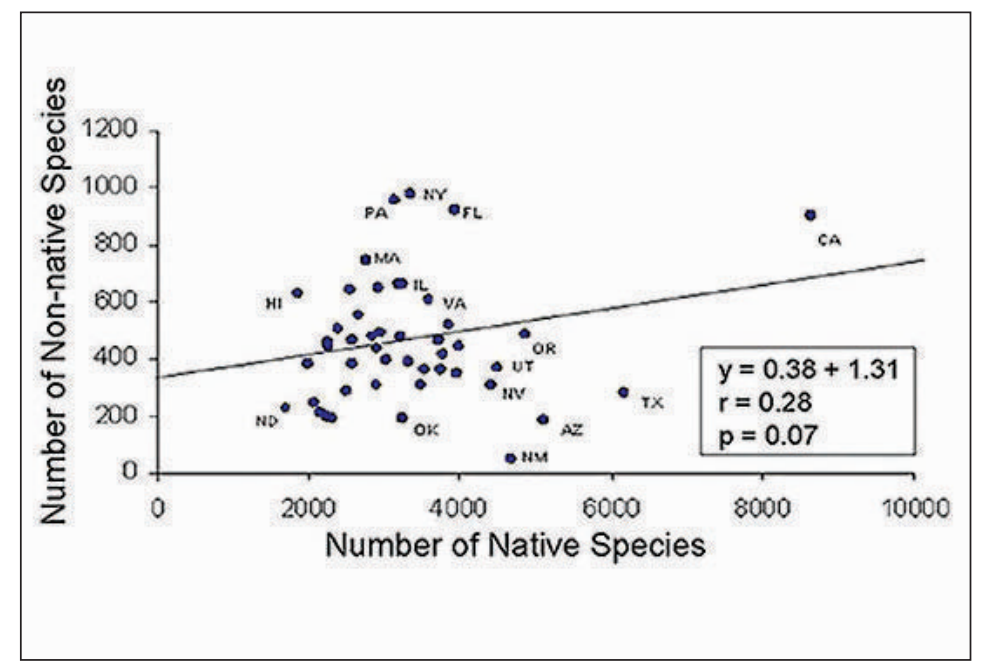

Figure 2. Correlation of native and non-native species richness by state. Data: Biota of North America Program. 


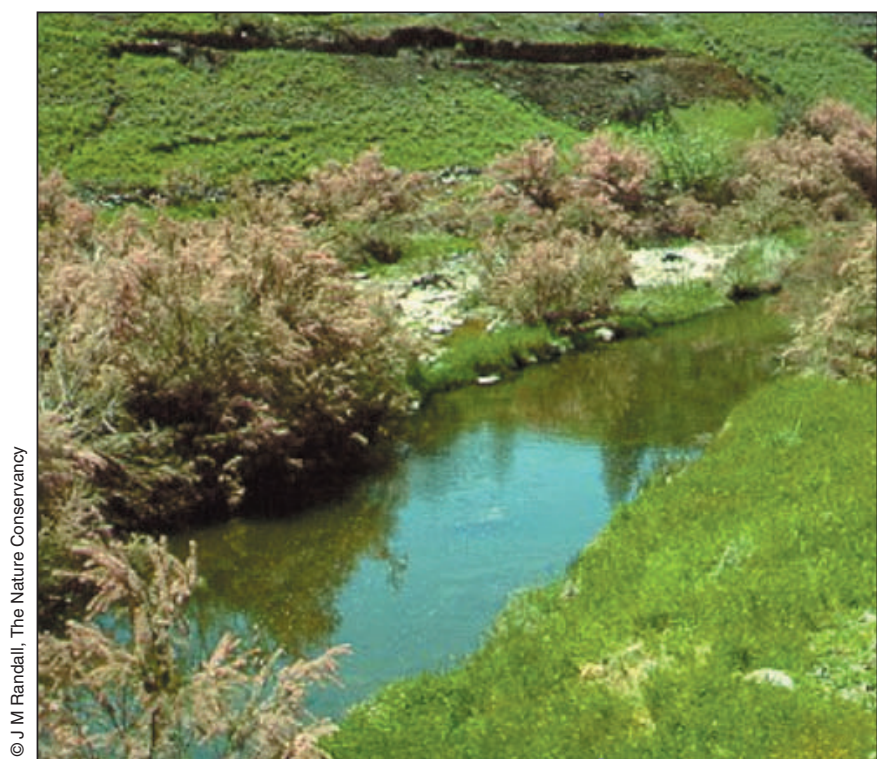

Figure 3. Salt cedar (Tamarix ramosissima), a common invader of species-rich riparian zones throughout the southwest US.

be extirpated); increased pulses of available resources (more light, nitrogen, or water in response to high turnover); and therefore more opportunities for nonnative plants to become established (Stohlgren et al. 1999). This is the case for tamarisk invasion throughout riparian zones in the US Southwest (Figure 3).

We hope the disparity between the results of smallscale experiments and the large-scale areas reported here does not go unnoticed. The patterns and processes in controlled experiments at small spatial scales in protected environments may reveal little about the patterns and processes that operate in larger, more complex ecosystems (Rejmánek 1989; Stohlgren 2002; Stohlgren et al. 2002). In light of the broader-scale observations (Table 1; Figures 1 and 2), future experiments and models should not assume that biodiversity is a barrier to invasion (eg Naeem et al. 2000; Kennedy et al. 2002). Instead, ecologists must work to better understand processes that promote invasion in species-rich habitats at scales larger than plant neighborhoods. We must begin by asking the question, "How are so many species-rich areas successfully invaded?"

\section{Acknowledgements}

We thank Ken Stolte, Misako Nishino, Catherine Crosier, Rick Shory, Kelly Rimar, Sara Simonson, and Geneva Chong for supplying data and assisting with data management. John Kartesz helped in plant species identification, and Phillip Chapman and Robin Reich consulted on statistics. Funding was provided by the US Fish and Wildlife Service, the US Forest Service Forest Health Monitoring Program, and the US Geological Survey.

\section{References}

Biota of North America Program of the North Carolina Botanical Garden (BONAP). 2002. Flora database for North America. www.bonap.org. Viewed 15 November 2002.

Case TJ. 1990. Invasion resistance arises in strongly interacting species-rich model competition communities. P Natl Acad Sci USA 87: 9610-14.

Cline SP, Alexander SA, and JE Barnard (Eds). 1995. Environmental monitoring and assessment program, forest health monitoring program, quality assurance project plan for detection monitoring project. In: Environmental monitoring systems laboratory report. Las Vegas, NV: United States Environmental Protection Agency. EPA/620/R-95/002.

Davis MA, Grime JP, and Thompson K. 2000. Fluctuating resources in plant communities: a general theory of invasibility. J Ecol 88: 528-34.

Elton C. 1958. The ecology of invasions by animals and plants. London: Methuen and Company.

Grime PJ. 1973. Control of species density in herbaceous vegetation. J Environ Manage 1: 151-167.

Kennedy TA, Naeem S, Howe K, et al. 2002. Biodiversity as a barrier to ecological invasion. Nature 417: 636-38.

Knops JH, Tilman D, Naeem S, and Howe KM. 1997 Biodiversity and plant invasions in experimental grassland plots. B Ecol Soc Amer 78: 125.

Levine JM. 2000. Species diversity and biological invasions: relating local processes to community pattern. Science 288: 761-63.

Levine JM and D'Antonio CM. 1999. Elton revisited: A review of evidence linking diversity and invasibility. Oikos 87: 15-26.

Lonsdale WM. 1999. Global patterns of plant invasions and the concept of invasibility. Ecology 80: 1522-36.

Naeem S, Knops JMH, Tilman D, et al. 2000. Plant diversity increases resistance to invasion in the absence of covarying extrinsic factors. Oikos 91: 97-108.

Post WM and Pimm SL. 1983. Community variability and foodweb stability. Math Biosci 64: 169-92.

Rejmánek M. 1989. Invasibility of plant communities. In: Drake JA, Mooney HA, di Castri F, et al. (Eds). Biological invasions: a global perspective. New York: John Wiley and Sons. p 369-88.

Rejmánek M. 1996. Species richness and resistance to invasion. In Orians G, Dirzo R, and Cushman JH (Eds). Biodiversity and ecosystem processes in tropical forests. New York: SpringerVerlag. p 153-72

Rejmánek M. 1999. Invasive plant species and invasible ecosystems. In: Sandlund OT, Schei JH, and Viken $\AA$ (Eds). Invasive species and biodiversity management. Dordrecht, Germany: Kluwer Academic Publishers. p 79-102.

Rummel DJ and Roughgarten J. 1983. Some differences between invasion-structured and co-evolutionary-structured competitive communities. Oikos 41: 477-86.

Stohlgren TJ. 2002. Beyond theory of plant invasions: lessons from the field. Comm Theor Biol 7: 355-79.

Stohlgren TJ, Binkley D, Chong GW, et al. 1999. Exotic plant species invade hot spots of native plant diversity. Ecol Monogr 69: 25-46.

Stohlgren TJ, Chong GW, Kalkhan MA, and Schell LD. 1997. Rapid assessment of plant diversity patterns: a methodology for landscapes. Env Monit Assess 48: 25-43.

Stohlgren TJ, Chong GW, Schell LD, et al. 2002. Assessing vulnerability to invasion by non-native plant species at multiple scales. Environ Manage 29: 566-77.

Tilman D. 1999. The ecological consequences of changes in biodiversity: a search for general principles. Ecology 78: 81-92.

Turelli M. 1981. Niche overlap and invasion of competitors in random environments. Models without demographic stochasticity. Theor Popul Biol 20: 1-56. 